\title{
Paediatric Crossword Puzzle - 4
}

Manouri P. Senanayake ${ }^{1}$

Sri Lanka Journal of Child Health, 2009; 38: 43

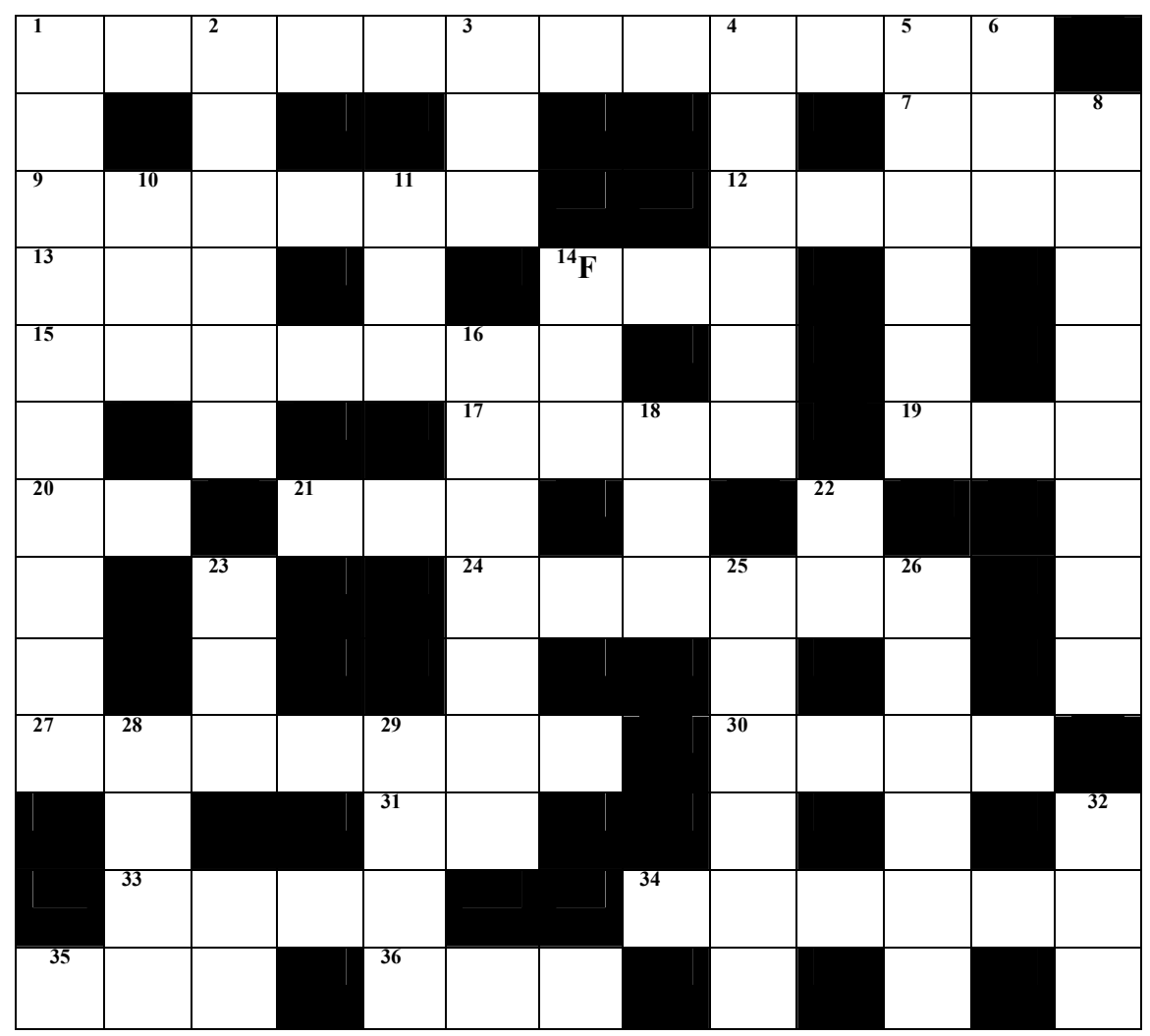

\section{Across}

1. Coating of antigen to facilitate its destruction

7. Snake more venomous than cobra

9. Gland which secrete melatonin

12. Tuberculosis of spine

13. Common cause of acute renal failure in children

14. Pituitary hormone showing a prepubertal rise

15. Benign tumour of glandular origin

17. Waiter's tip position of the hand

19. Vaccine falsely linked to autism

20. Intravenous ( $a b b r)$

21. Cause of crepitus in subcutaneous emphysema

24. Organism possesing two cell lines

27. Shape of $\mathrm{O}_{2}-\mathrm{Hb}$ dissociation curve

30. Cause of oesophagitis in gastric reflux

31. Differential diagnosis $(a b b r)$

33. Term for mother- child bond

34. Site of characteristic skin lesion in erythema infectiosum

35. Urinary catecholamine

36. Narrow complex tachycardia

\section{Down}

1. Infection of umbilical stump

2. Eye sign in hydrocephalus

3. Used to corrects cataract in children

4. Rickettsial infection causing fever \& skin rash

5. Defect in cardiac wall

6. Effective in malaria control

8. Vitamin C

10. Contraceptive method suitable for lactating mothers

11. --- rectal

14. Visual affection in hypermetropia

16. Splint that corrects genu varum

18. Name of a global pharmaceutical company (abbr)

22. Effectively treated by vasopressin

23. Anaphylaxis caused by this food item Is a contraindication for measles vaccine

25. Feature common to both anaemia and Kwashiokor

26. Precipitated by infections in cortisol deficient patients

28. Endocrine disease commonly presenting with ketoacidosis

29. Ratio determining statistical association

32. virus causing cold sores

${ }^{1}$ Professor of Paediatrics, Faculty of Medicine, University of Colombo See June 2009 issue for answers 